ORIGINAL ARTICLE

\title{
Injuries in youth amateur soccer and rugby players- comparison of incidence and characteristics
}

\author{
A Junge, $K$ Cheung, T Edwards, J Dvorak
}

Br J Sports Med 2004;38:168-172. doi: 10.1136/bjsm.2002.003020

See end of article for authors' affiliations

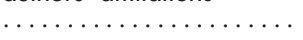

Correspondence to: Dr A Junge, Schulthess Klinik, FIFA-Medical Assessment and Research Centre (F-MARC) Lengghalde 2, Zurich 8008, Switzerland; ajunge@kws.ch

Accepted 31 March 2003
Objectives: In reviewing the literature on sports injuries, few studies could be found in which exposure related incidences of injury in different types of sport were compared. These studies indicated that ice hockey, handball, basketball, soccer, and rugby are popular team sports with a relatively high risk of injury. The aim of the study was to compare the characteristics and incidence of injuries in male youth amateur soccer and rugby players.

Methods: This prospective cohort study comprised an initial baseline examination to ascertain the characteristics of the players and their level of performance, and a one season observation period during which a physician visited the team weekly and documented all occurring injuries. Twelve soccer and 10 rugby school teams with male amateur players aged 14-18 years were selected for the study. 145 soccer and 123 rugby players could be followed up over one season.

Results: Comparison of the incidence of soccer and rugby injuries indicated that rugby union football was associated with a significantly higher rate of injury than soccer. The differences were pronounced for contact injuries, injuries of the head, neck, shoulder, and upper extremity, as well as for concussion, fractures, dislocations, and strains. Rugby players incurred 1.5 times more overuse and training injuries in relation to exposure time, and 2.7 times more match injuries than soccer players. Three rugby players but no soccer players had to stop their participation in sport because of severe injury.

Conclusion: The incidence of injury in New Zealand school teams playing soccer or rugby union is high, probably in part because of the low ratio of hours spent in training relative to hours spent playing matches. The development and implementation of preventive interventions to reduce the rate and severity of injury is recommended. a is commonly accepted that sport is beneficial for physical and mental health, but is also associated with a certain risk of injury. The relative risk of injury for a particular type of sport can only be calculated in comparison with others. Several authors have investigated the injury rate associated with a given type of sport, but the results of these studies cannot be compared with one another due to heterogeneous definitions, methods of data collection, observation periods, study designs, and sample characteristics. ${ }^{1-3}$ In reviewing the literature on sports injuries, only a few studies can be found in which the frequency of injury in different types of sport has been reported, and even fewer studies have compared exposure related incidences of injury. ${ }^{4-7}$

Backx et $a l^{4}$ conducted a longitudinal investigation of Dutch school children aged 8 to 17 years. Data concerning sports activity and sports injuries were gathered, retrospectively, twice within a seven month period. A sports injury was defined as any physical damage caused by an accident during physical education or during any sporting activity outside school, both organised and non-organised. Soccer was associated with the fourth highest incidence of injuries per 1000 hours of game, after basketball, handball, and korfball.

In a prospective study, all people in a Swedish municipality who attended a physician for an acute injury sustained while playing sport or performing physical exercise were investigated. ${ }^{5}$ Data on exposure time were collected from three different sources and estimated for the study population. In males aged 15 to 59 years, soccer resulted in the fourth highest incidence rate after ice hockey, horseback riding, and handball.

In another epidemiological study, two data sources were combined: Military Insurance provided information about all acute sports injuries diagnosed by a physician and the Swiss organisation "Youth and Sports" provided data about exposure time with regards to involvement in sport. ${ }^{6}$ In the male population aged from 14 to 20 years, soccer resulted in the third highest incidence rate after ice hockey and handball.

Although none of the above cited studies investigated rugby, in a national survey in England and Wales this sport resulted in the highest incidence of exercise related injuries. ${ }^{7}$ Using a postal questionnaire, adults aged 16 to 45 years were asked about their participation in sport and sports injuries incurred during the previous 28 days. To ensure full reporting of all injuries incurred during the reference period, injury was defined as "any injury or illness, however minor, through taking part in any of the activities [you] listed". "Trivial" injuries were distinguished from "substantive" injuries, where the latter were defined as those restricting participation in usual activities for at least one day and for which treatment had been sought. The risk of sustaining any injury per episode of participation was highest in rugby, followed by soccer and field hockey. The risk of a "substantive" injury was also highest in rugby, with soccer and hockey ranking in third and fourth places after martial arts.

Ice hockey, handball, basketball, soccer, and rugby are clearly types of sport with a relatively high risk of injury. American football, which was not considered in the studies mentioned above, because all were conducted in Europe, should also be included in this group of popular high risk team sports. Injuries in these team sports should be investigated in detail using the same definition of injury, mode of data collection, population characteristics, and

Abbreviations: RG, rugby group; $S G$, soccer group 
methods of analysis. As a first step in this direction, the present study reports the results of a comparison of injury rates in male youth amateur soccer and rugby players.

\section{Soccer}

Soccer is the most popular sport in the world with approximately 200000 professional and 240 million amateur players. A soccer match is played with two teams of 11 players (including one goalkeeper). A match comprises two halves of 45 minutes with an interval of 15 minutes. Shin guards represent the only compulsory protective equipment to be worn during matches (for details of rules see www.fifa.org).

The majority of soccer injuries are caused by trauma; the proportion of overuse injuries accounts for between $9 \%$ and $34 \%$ of all injuries. ${ }^{8} 9$ Soccer injuries affect predominately the ankle and knee as well as the muscles of the thigh and calf. $^{10}{ }^{11}$ The incidence of soccer injury has been investigated in several studies, and varies for male outdoor players $(\geqslant 16$ years) from 12-35 injuries per 1000 match hours. ${ }^{12}{ }^{13}$ For youth players, the reported incidences range from 0.5-13.7 injuries per 1000 hours exposure. ${ }^{14}{ }^{15}$ Specific analysis of youth soccer players has shown that the incidence of injury increases with age. ${ }^{516-18}$

\section{Rugby}

Rugby is a popular sport and is second only to soccer in terms of the number of nations in which it is played. ${ }^{19}$ At least two different types of rugby have to be distinguished: rugby league and rugby union. The incidence of injuries is substantially lower in rugby union than in rugby league. ${ }^{2021}$ The present study focuses only on rugby union. A rugby union match is played by two teams of 15 players a side (eight forwards and seven backs). A match comprises two halves of 40 minutes with a 5-10 minute half time break. Rugby union is a full body contact game but no protective equipment is compulsory (for details of rules see www.irb. com). However, a New Zealand Rugby Union domestic safety law variation mandates the compulsory wearing of mouthguards in all matches below international level played in New Zealand.

In rugby union most of the injuries affect the lower limbs, followed by the head and neck or upper limbs in varying orders. $^{22-26}$ The incidence of rugby injuries in adult male players varies from 12-53 injuries per 1000 playing hours. ${ }^{25}$ For schoolboys, a game injury rate of between 7-65.8 injuries per 1000 game hours has been reported. ${ }^{26}{ }^{27}$ The incidence of injury in youth players seems to increase with age. ${ }^{26} 28$

\section{METHODS}

This prospective cohort study comprised an initial baseline examination to ascertain the characteristics of the players and their level of performance, and a one season observation period during which an independent physician visited the team weekly and documented all injuries incurred by the players. The baseline examination took part in February 2001 and the follow up lasted from March to August 2001.

The soccer and rugby teams were chosen from different schools in Auckland (New Zealand) in an attempt to include a wide range of players from different social classes and races (Maori, Polynesian, and European players). For the soccer group (SG), seven first and five second XI school teams were selected for the study, and for the rugby group (RG), five first and five second XV school teams. In each case, the teams comprised male amateur players aged 14-18 years and had no on site team physician or physiotherapist responsible for looking after the players. Participation was voluntary. Coaches and players were informed that they were taking part in an epidemiological study on the incidence of injuries in different types of sports.

After giving their informed consent, all players took part in a baseline examination which included a medical examination of the upper extremity, spine, hip, knee, and ankle, a sports test and a self administered questionnaire concerning medical history, psychological characteristics, and aspects of training and playing soccer (for the SG) or rugby (for the $R G$ ). The follow ups were conducted by physicians (experienced in orthopaedics or sports medicine) on a weekly basis. Each team had one physician who visited the team once per week, asked the players about physical complaints, and examined their injuries. All injuries were described in relation to their type and location, and the duration of the subsequent limitation in performance. If a new injury was incurred, the player was asked about the circumstances under which it had occurred. The amount of training and matches was recorded for each player individually by the coaches. All information was documented on specially designed forms. The study was approved by the local ethics committee.

\section{Definition of injury}

An injury was defined as any physical complaint caused by soccer (in the SG) or rugby (in the RG) during school training and matches. The duration of absence due to an injury was categorised according to the severity grading of the National Injury Registration System (NAIRS): up to one week, 8-21 days, or more than 21 days. $^{3}$

An injury was categorised as overuse if it was caused by repetitive micro trauma with no identifiable traumatic event. Non-contact injuries included overuse injuries. The classification of an injury as caused without or by contact with another player was based on information about the circumstances of the injury given by the player.

\section{Calculation of incidence}

The incidence of injury was calculated per player per season as well as per 1000 hours of exposure (sum of training and match playing hours). In order to analyse the incidence of the injury in more detail, two additional indexes were computed, (1) the number of match injuries in relation to the time spent in matches and (2) the number of overuse injuries and injuries during training in relation to the time spent in training.

\section{Statistical analysis}

Only players with complete weekly follow ups for the entire study period were included in the analysis of differences in the incidence and characteristics of injury between soccer and rugby. Players who could not be followed up for the whole season (dropouts) were compared with the study group for potential bias. Methods applied were descriptive, frequencies, and cross tabulation. Differences between groups were examined using $t$ tests or $\chi^{2}$ test; incidences of injury were compared by calculating $\mathrm{z}$ values. ${ }^{29}$ Significance was accepted at the $5 \%$ level.

\section{Analysis of dropouts}

Out of the 351 players who participated in the baseline examination $83(23.6 \%)$ dropped out of the cohort study. The majority of dropouts were players not selected for the team taking part in the study or the player leaving the team or the school. In the RG, three players were excluded from the analysis because they suffered from a severe injury at baseline, and two others were excluded because they incurred severe injuries from other sports during the follow up period. 
Within the SG and the RG, players with complete weekly follow ups and dropouts did not differ in age, skill level of their teams, position on the field, and the results of almost all performance test assessed at baseline (exception for the SG, distance of 12 minute run; for the RG, pulse rate after 12 minute run). There was no significant difference in the rate of dropouts between the $S G(n=52 ; 26 \%)$ and the $R G$ $(\mathrm{n}=31 ; 21 \%)$.

\section{Study group}

Complete weekly follow ups were available in 145 soccer and 123 rugby players. On average the players were 16.7 (SD 0.97) years and had played soccer or rugby for 4.3 (SD 2.2) years in a school team. Most of the soccer players were midfield players $(\mathrm{n}=49 ; 34 \%)$ or defenders $(\mathrm{n}=39 ; 27 \%)$; attackers $(\mathrm{n}=22 ; 15 \%)$ were less numerous. Twenty six soccer players ( $18 \%)$ played in more than one position. Only nine $(6 \%)$ goalkeepers participated in the study. In the RG, the numbers of forwards $(\mathrm{n}=59 ; 48 \%)$ and backs $(\mathrm{n}=64 ; 52 \%)$ were similar.

Although teams for both groups were selected so as to be of a similar age and skill level, rugby players were significantly older, taller, and heavier than soccer players (see table 1).

\section{RESULTS}

During the follow up period, 261 injuries were recorded for the soccer players and 340 injuries for the rugby players, equivalent to 1.8 injuries per player per season in the SG and 2.8 in the RG.

In both groups, two thirds of all injuries were incurred during matches, $20 \%$ during training sessions, and 15\% were due to overuse. Significant differences between soccer and rugby players were observed in the distribution of contact and non-contact injuries as well as in location, type, and severity of injuries (table 2). Rugby players incurred two thirds of their injuries during contact with another player whereas for soccer players, contact and non-contact injuries were equally distributed. In soccer players, $77 \%$ of injuries affected the lower extremities, but in rugby players less than half of the injuries $(43 \%)$ involved the lower extremities. In rugby players, injuries of the shoulder and the upper extremities were substantially more frequent than in the soccer players. Strains, sprains, and contusions were the most frequent types of injury in both groups, but in the RG more fractures, dislocations, and cases of concussion were incurred compared with the SG. In the SG, a significantly higher percentage of injuries $(\mathrm{n}=80 ; 30.7 \%)$ resulted in subsequent absence from at least one match or training session, compared with the RG $(\mathrm{n}=71 ; 20.9 \%)$. However, three

Table 1 Comparison of baseline characteristics of soccer and rugby players

\begin{tabular}{|c|c|c|c|c|}
\hline & \multicolumn{2}{|c|}{$\begin{array}{l}\text { Soccer players } \\
(n=145)\end{array}$} & \multicolumn{2}{|c|}{$\begin{array}{l}\text { Rugby players } \\
(n=123)\end{array}$} \\
\hline & Mean & (SD) & Mean & (SD) \\
\hline Age & 16.4 & (1.0) & 17.0 & $(0.84) t=5.11^{*}$ \\
\hline Height (m) & 1.74 & $(0.06)$ & 1.78 & $(0.06) t=4.34^{*}$ \\
\hline Weight (kg) & 66.4 & $(9.16)$ & 82.5 & $(12.3) t=12.2^{*}$ \\
\hline BMI $\left(\mathrm{kg} / \mathrm{m}^{2}\right)$ & 21.7 & $(2.58)$ & 25.9 & $(3.38) t=11.7^{*}$ \\
\hline $\begin{array}{l}\text { Playing the sport under } \\
\text { investigation in a school } \\
\text { team (years) }\end{array}$ & 4.30 & $(2.40)$ & 4.34 & $(1.96)$ NS \\
\hline Skill level of the team & $\mathrm{n}$ & $(\%)$ & $\mathrm{n}$ & $(\%) \quad N S$ \\
\hline High & 98 & (67.6) & 71 & $(57.7)$ \\
\hline Low & 47 & (32.4) & 52 & (42.3) \\
\hline
\end{tabular}

NS, no significant difference between soccer and rugby players. *Significant difference between soccer and rugby players, $\mathrm{p}<0.001$.
Table 2 Comparison of injuries in soccer $(n=145)$ and in rugby $(n=123)$ players

\begin{tabular}{|c|c|c|c|c|}
\hline & \multicolumn{2}{|c|}{$\begin{array}{l}\text { Soccer injuries } \\
(n=261)\end{array}$} & \multicolumn{2}{|c|}{$\begin{array}{l}\text { Rugby injuries } \\
(\mathrm{n}=340)\end{array}$} \\
\hline & $n$ & $(\%)$ & $n$ & (\%) \\
\hline Circumstances & & & & NS \\
\hline Overuse & 39 & (14.9\%) & 45 & (13.2\%) \\
\hline Training & 49 & (18.8\%) & 70 & $(20.6 \%)$ \\
\hline Match & 173 & $(66.3 \%)$ & 225 & $(66.2 \%)$ \\
\hline Contact & & & & $\chi^{2}=55.5^{*}$ \\
\hline No & 135 & $(51.7 \%)$ & 113 & $(33.2 \%)$ \\
\hline Yes & 126 & (48.3\%) & 227 & $(66.8 \%)$ \\
\hline Location of injury & & & & $\chi^{2}=110^{*}$ \\
\hline Head & 11 & $(4.2 \%)$ & 31 & $(9.1 \%)$ \\
\hline Cervical spine, neck & 2 & $(0.8 \%)$ & 23 & $(6.8 \%)$ \\
\hline Shoulder & 2 & $(0.8 \%)$ & 65 & $(19.1 \%)$ \\
\hline Upper extremity & 13 & $(5.0 \%)$ & 45 & $(13.2 \%)$ \\
\hline Thoracic, lumbar spine & 17 & $(6.5 \%)$ & 17 & $(5.0 \%)$ \\
\hline Trunk & 7 & $(2.7 \%)$ & 7 & $(2.1 \%)$ \\
\hline Hip & 8 & $(3.2 \%)$ & 7 & $(2.1 \%)$ \\
\hline Groin & 16 & $(6.1 \%)$ & 10 & $(2.9 \%)$ \\
\hline Thigh & 44 & $(17.0 \%)$ & 30 & (8.8\%) \\
\hline Knee & 39 & $(15.0 \%)$ & 39 & (11.5\%) \\
\hline Lower leg & 42 & (16.1\%) & 31 & $(9.1 \%)$ \\
\hline Ankle & 45 & $(17.2 \%)$ & 24 & (7.1\%) \\
\hline Foot & 15 & $(5.8 \%)$ & 11 & $(3.2 \%)$ \\
\hline Type of injury & & & & $\chi^{2}=25.9+$ \\
\hline Concussion & 3 & $(1.2 \%)$ & 10 & $(2.9 \%)$ \\
\hline Fracture & 3 & $(1.2 \%)$ & 14 & $(4.1 \%)$ \\
\hline Dislocation & 3 & $(1.2 \%)$ & 11 & $(3.2 \%)$ \\
\hline Lesion of meniscus & 3 & $(1.2 \%)$ & 2 & $(0.6 \%)$ \\
\hline Lesion of MCL & 1 & $(0.3 \%)$ & 0 & \\
\hline Subluxation & 0 & & 5 & $(1.7 \%)$ \\
\hline Strain & 83 & $(31.8 \%)$ & 123 & $(36.2 \%)$ \\
\hline Sprain & 53 & $(20.3 \%)$ & 58 & $(17.1 \%)$ \\
\hline Contusion & 74 & $(28.4 \%)$ & 73 & $(21.5 \%)$ \\
\hline Bursitis/tendinitis & 9 & $(3.5 \%)$ & 11 & $(3.2 \%)$ \\
\hline Periostitis & 2 & $(0.8 \%)$ & 5 & $(1.5 \%)$ \\
\hline Lesion of skin & 12 & $(4.6 \%)$ & 10 & $(2.9 \%)$ \\
\hline Others & 15 & $(5.8 \%)$ & 18 & (5.3\%) \\
\hline Duration of absence & & & & $\chi^{2}=10.7 \dagger$ \\
\hline No absence & 181 & (69.3\%) & 269 & $(79.1 \%)$ \\
\hline 1-7 days & 52 & (19.9\%) & 37 & (10.9\%) \\
\hline 8-21 days & 19 & $(7.3 \%)$ & 26 & $(7.6 \%)$ \\
\hline$>21$ days & 9 & $(3.4 \%)$ & 8 & $(2.4 \%)$ \\
\hline
\end{tabular}

NS, no significant difference between soccer and rugby players. *Significant difference between soccer and rugby players: $p<0.001$. †Significant difference between soccer and rugby players: $p<0.05$.

rugby players, but no soccer players, had to stop their participation in sport due to an injury (shoulder dislocation $(\mathrm{n}=2)$, ACL tear $(\mathrm{n}=1))$.

Soccer and rugby players spent almost the same amount of time training for their sport, but soccer players spent significantly more time in matches than did rugby players (table 3 ). This resulted in a significantly higher exposure time in the SG compared with the RG. Calculating the incidence of injury in relation to exposure time, rugby players incurred significantly more injuries than soccer players (RG 49.4 v SG 27.9; $\mathrm{z}=7.07, \mathrm{p}<0.001$ ). The differences were not only significant for overall incidence of injury but also for the incidence of contact injuries, injuries of the head, neck, shoulder, and upper extremity, as well as for concussion, fractures, dislocations, subluxations, and strains (table 3).

Analysing overuse and training injuries in relation to time spent in training, and match injuries in relation to time spent in matches, rugby players incurred 1.5 times more overuse and training injuries and 2.7 times more match injuries than did football players. If only injuries leading to subsequent absence from training sessions or matches were considered, the difference between the groups was significant for match injuries but not for overuse/training injuries. 
Table 3 Comparison of exposure time and incidence of injury in soccer and in rugby players

\begin{tabular}{|c|c|c|}
\hline & $\begin{array}{l}\text { Soccer players } \\
(n=145) \\
\text { Mean (SD) }\end{array}$ & $\begin{array}{l}\text { Rugby players } \\
(n=123) \\
\text { Mean (SD) }\end{array}$ \\
\hline Training hours & $39.5(17.1)$ & $41.8(11.6)$ \\
\hline Match hours & $25.1(11.4)$ & $14.1(5.8) t=9.68^{*}$ \\
\hline Exposure (hours) & \multicolumn{2}{|c|}{ Injuries per $1000 \mathrm{hrs}$ exposure } \\
\hline \multicolumn{3}{|l|}{ Contact } \\
\hline No & 14.4 & 16.4 \\
\hline Yes & 13.5 & $33.0 z=7.54^{*}$ \\
\hline \multicolumn{3}{|l|}{ Location of injury } \\
\hline Head & 1.12 & $4.51 \mathrm{z}=3.81^{*}$ \\
\hline Cervical spine, neck & 0.21 & $3.35 z=4.58^{*}$ \\
\hline Shoulder & 0.21 & $9.45 z=8.21^{*}$ \\
\hline Upper extremity & 1.39 & $6.54 z=4.93^{*}$ \\
\hline Thoracic, lumbar spine & 1.82 & 2.47 \\
\hline Trunk & 0.75 & 1.02 \\
\hline Hip & 0.86 & 1.02 \\
\hline Groin & 1.71 & 1.45 \\
\hline Thigh & 4.70 & 4.36 \\
\hline Knee & 4.17 & 5.67 \\
\hline Lower leg & 4.49 & 4.51 \\
\hline Ankle & 4.81 & 3.49 \\
\hline Foot & 1.60 & 1.60 \\
\hline \multicolumn{3}{|l|}{ Type of injury } \\
\hline Concussion & 0.32 & $1.45 z=2.28 \ddagger$ \\
\hline Fracture & 0.32 & $2.04 z=3.04 \dagger$ \\
\hline Dislocation & 0.32 & $1.60 z=2.49 \ddagger$ \\
\hline Lesion of meniscus & 0.32 & 0.29 \\
\hline Lesion of MCL & 0.11 & 0 \\
\hline Subluxation & 0.0 & $0.73 z=2.37 \ddagger$ \\
\hline Strain & 8.87 & $17.9 z=4.57^{*}$ \\
\hline Sprain & 5.67 & 8.44 \\
\hline Contusion & 7.91 & 10.6 \\
\hline Bursitis/tendinitis & 0.96 & 1.60 \\
\hline Periostitis & 0.21 & 0.73 \\
\hline Lesion of skin & 1.28 & 1.45 \\
\hline Others & 1.60 & 2.62 \\
\hline \multicolumn{3}{|l|}{ Duration of absence } \\
\hline No absence & 19.4 & $39.1 z=6.76^{*}$ \\
\hline $1-7$ days & 5.56 & 5.38 \\
\hline 8-21 days & 2.03 & $3.78 z=2.10 \ddagger$ \\
\hline$>21$ days & 0.96 & 1.16 \\
\hline \multicolumn{3}{|l|}{$\begin{array}{l}\text { Overuse/training injuries } \\
\text { per } 1000 \text { training hours }\end{array}$} \\
\hline Total & 15.4 & $22.4 \mathrm{z}=2.71 \dagger$ \\
\hline Without absence & 11.7 & $18.1 z=2.74 \dagger$ \\
\hline With absence & 3.67 & 4.28 \\
\hline \multicolumn{3}{|l|}{$\begin{array}{l}\text { Match injuries per } 1000 \\
\text { match hours }\end{array}$} \\
\hline $\begin{array}{l}\text { match hours } \\
\text { Total }\end{array}$ & 47.5 & $129.8 z=10.6^{*}$ \\
\hline Without absence & 31.3 & $101.5 z=10.3^{*}$ \\
\hline With absence & 16.2 & $28.3 z=2.93 \dagger$ \\
\hline \multicolumn{3}{|c|}{$\begin{array}{l}\text { *Significant difference between soccer and rugby players, } \mathrm{p}<0.001 \text {. } \\
\text { †Significant difference between soccer and rugby players, } \mathrm{p}<0.01 \text {. } \\
\text { †Significant difference between soccer and rugby players, } \mathrm{p}<0.05 \text {. }\end{array}$} \\
\hline
\end{tabular}

No differences in the incidence or characteristics of injuries for the different playing positions were observed for either for soccer or rugby.

To evaluate possible effects of age on the incidence of injury, the players aged 16 and 17 years were analysed separately. The incidence of injury increased from the 16 to the 17 year old soccer players $(23.5 v 35.1)$, whereas it seemed to be stable in rugby players of this age $(50.1 v 50.6)$. In both age groups, the exposure related incidence of injury was significantly higher in the RG than in the SG.

\section{DISCUSSION}

The present study is a prospective investigation of the incidence and characteristics of injury in youth amateur soccer and rugby players. Although the teams were selected to be of a similar age and skill level, the SG and the RG differed substantially in almost all baseline characteristics as well as in the amount of time spent in matches. The proportion of high and low skill level teams did not vary significantly between the groups. Differences in anthropometric characteristics of soccer and rugby players reflect the distinct nature of the two sports. However, studies examining the effects of these characteristics on the incidence of injury within a sport have shown that they are of minor importance. ${ }^{30}{ }^{31}$ Possible effects of differences in age between the groups were evaluated by analysing two age groups separately.

Before the results of the comparison of soccer and rugby injuries are discussed, the incidence of injury for each sport will be compared with the incidences reported in other studies of injury in youth players, for the given sport. One of the main problems encountered in attempting to compare incidences of sports injuries reported in the literature is that different evaluation methods and definitions of injury have been used. ${ }^{1-3}$ A definition of injury based on absence from the relevant sport would seem to be suitably objective, but it is associated with several problems. ${ }^{3}$ For example, in the present study, eleven fractures that did not result in subsequent absence from training or the match would have been neglected. Therefore, we decided to use a broad definition of injury and, in addition, to present the number and incidence of injuries that caused the player to miss at least one training session or match. Another important aspect in comparing the incidence of sports injuries is the influence of the ratio of time spent in training relative to time spent playing matches. Usually, more injuries occur during matches than during training sessions and, as such, differences in the ratio of training and match hours may bias calculations of the overall incidence of injury. For this reason, it is recommended that the incidence of match injuries in relation to the time spent in matches, and of training injuries in relation to the time spent in training, are reported and compared separately.

The incidence of soccer injuries in the present study was substantially higher than those reported by Peterson et $a l^{15}$ and Nicholl et $\mathrm{al}^{7}$ using the same definition of injury. It was also higher than the incidences reported for Swiss youth amateur players serving as a control group in an intervention study $y^{32}$ and for soccer players of a similar age from Alsace and Czech Republic ${ }^{33}$ when the data of the present study were recalculated using the injury definitions of those studies. It has to be mentioned that the players from Alsace, Czech Republic, and Switzerland were club players who spent more time in training than did the school teams assessed in the present study. The training:match time ratio in youth players from Alsace was 4.5, from Czech Republic 4.7, and from Switzerland 3.3, but it was only 1.6 for the SG in the present study. If the exposure related incidences of training injuries and match injuries are compared separately, the differences between the SG in New Zealand and youth players from Alsace, Czech Republic, and Switzerland are less pronounced.

The incidence of rugby injuries in the present study is similar to that reported by Nicholl et al for a group aged 1645 years. In the New Zealand Rugby Injury and Performance project, only injuries that caused the player to seek medical attention or to miss at least one scheduled game or team practice were recorded. ${ }^{31}$ In the 54 schoolboys in this study, the incidence of game injuries was 6.2 per 100 player games, which equates to approximately 47 injuries per 1000 match hours. This incidence is higher than that for match injuries with subsequent absence, but substantially lower than that for all match injuries found in the present study. Durie and Munroe $^{27}$ assessed all players that left the field because of an injury, or complained of injury at the completion of the match as well as all training injuries. The incidence of match injuries per 1000 playing hours was 65.8 in the lst XV players and 35.0 in the 2 nd XV players. Nathan $e t a l^{34}$ and Roux et $a l^{26}$ 


\section{Take home message}

The incidence of injury in New Zealand school teams playing soccer or rugby union is high, probably in part because of the low ratio of hours spent in training relative to hours spent playing matches. Rugby resulted in a higher incidence of injury, especially of match injuries, than soccer. The development and implementation of preventive interventions to reduce the rate and severity of injury is recommended.

recorded rugby injuries only if they were severe enough to prevent the player from returning to rugby for at least seven days, and, in addition, all concussions. The incidence in the first study of the authors, where only one school was monitored, ${ }^{34}$ was one match injury per 84 boy hours match play, equivalent to 12 injuries per 1000 match hours. In a later study, where 20 schools were monitored, ${ }^{26}$ the incidence was 142 boy hours match play, equivalent to seven injuries per 1000 match hours. Roux et $a^{26}$ concluded that this difference was due to underreporting by the schools monitored through correspondence. However, the incidences of injury reported in both studies are substantially lower than the incidence of match injuries in the present study when the data of this study were recalculated using the injury definition of those studies.

Comparison of the incidence of soccer and rugby injuries clearly indicates that rugby union is associated with a higher rate of injury than soccer. Specifically, the incidence of match injuries was more than twice as high in rugby players compared with soccer players. The greater degree of severity of rugby injuries was shown by the higher incidence of fractures and dislocations in the RG compared with the SG, and was further exemplified by the fact that three rugby players but no soccer players had to stop their participation in sport because of injury.

Both soccer and rugby injuries most frequently affected the lower extremity, consistent with the reports of other authors. ${ }^{10} 112325$ Injuries of the shoulder, upper extremity, and head were more frequently incurred by rugby than by soccer players.

An increase in the incidence of injury with age has been shown previously for soccer ${ }^{516-18}$ as well as for rugby. ${ }^{26}$ In the present study, only the age groups of 16 and 17 year old players included a sufficient number of players for analysis. The previously described trend was found for soccer but not for rugby players. However, this result should be interpreted with caution due to the relatively small sample sizes. The analysis was mainly conducted to show that the results of the present study were not biased by the significantly younger age of the SG compared with the RG.

\section{Authors' affiliations}

A Junge, Schulthess Klinik, FIFA-Medical Assessment and Research Centre (F-MARC), Zurich, Switzerland

K Cheung, T Edwards, Adidas Sports Medicine, Goodfellow Unit, University of Auckland, New Zealand

J Dvorak, FIFA-Medical Assessment and Research Centre (F-MARC), Schulthess Klinik, Zurich, Switzerland

\section{REFERENCES}

1 Finch CF. An overview of some definitional issues for sports injury surveillance. Sports Med 1997;24:157-63.

2 Junge A, Dvorak J. Influence of definition and data collection on the incidence of injuries in football. Am J Sports Med 2000;28(Suppl 5):S40-6.

3 van Mechelen W, Hlobil H, Kemper HCG. Incidence, severity, aetilogy and prevention of sports injuries. Review of concepts. Sports Med 1992;14:82-99.

4 Backx FJ, Beijer HJ, Bol E, et al. Injuries in high-risk persons and high-risk sports. Am J Sports Med 1991;19:124-30.

5 de Loes M, Goldie I. Incidence rate of injuries during sport activity and physical exercise in a rural Swedish municipality: incidence rates in 17 sports. Int J Sports Med 1988;9:461-7.

6 de Loës M. Epidemiology of sports injuries in the Swiss organization "Youth and Sports" 1987-1989. Injuries, exposure and risks of main diagnoses. Int J Sports Med 1995; 16:134-8.

7 Nicholl JP, Coleman P, Williams BT. The epidemiology of sports and exercise related injury in the United Kingdom. Br J Sports Med 1995;29:232-8.

8 Arnason A, Gudmundsson A, Dahl HA, et al. Soccer injuries in Iceland. Scand J Med Sci Sports 1996;6:40-5.

9 Nielsen $A B, Y$ de J. Epidemiology and traumatology of injuries in soccer. Am J Sports Med 1989;17:803-7.

10 Fried T, Lloyd GJ. An overview of common soccer injuries. Management and prevention. Sports Med 1992;14:269-75.

11 Inklaar H. Soccer injuries. I: Incidence and severity. Sports Med $1994 ; 18: 55-73$

12 Inklaar H. Soccer injuries. II: Aetiology and prevention. Sports Med 1994; 18:81-91.

13 Dvorak J, Junge A. Football injuries and physical symptoms-Review of the literature, part I. Am J Sports Med 2000;28(Suppl 5):S3-9

14 Sullivan JA, Gross RH, Grana WA, et al. Evaluation of injuries in youth soccer. Am J Sports Med 1980;8:325-7.

15 Peterson L, Junge A, Chomiak J, et al. Incidence of injuries and symptoms due to football in different age and skill level groups. Am J Sports Med 2000;28(Suppl 5):S51-7.

16 Inklaar H, Bol E, Schmikli SL, et al. Injuries in male soccer players: team risk analysis. Int J Sports Med 1996;17:229-34.

17 Schmidt-Olsen S, Bunemann LK, Lade V, et al. Soccer injuries of youth. Br J Sports Med 1985; 19:161-4.

18 Schmidt-Olsen S, Jorgensen U, Kaalund S, et al. Injuries among young soccer players. Am J Sports Med 1991;19:273-5.

19 Hughes DC, Fricker PA. A prospective survey of injuries to first-grade rugby union players. Clin J Sports Med 1994;4:249-56.

20 Pringle RG, McNair P, Stanley S. Incidence of sporting injury in New Zealand youths aged 6-15 years. Br J Sports Med 1998;32:49-52.

21 Seward H, Orchard J, Hazard H, et al. Football injuries in Australia at élite level. Med J Aust 1993;159:298-301.

22 Addley K, Farren J. Irish Rugby Injury Survey: Dungannon Football Club (1986-87). Br J Sports Med 1988;22:22-4

23 Bird YN, Waller SE, Marshall SW, et al. The New Zealand Rugby Injury and Performance Project: V. Epidemiology of a season of rugby injury. Br J Sports Med 1998;32:319-25.

24 Clark DR, Roux C, Noakes TD. A prospective study of the incidence and nature of injuries to adult rugby players. S Afr Med J 1990;77:559-62.

25 Garraway M, MacLeod D. Epidemiology of rugby football injuries. Lancet 1995:345:229-33

26 Roux CE, Goedeke R, Visser GR, et al. The epidemiology of schoolboy rugby injuries. S Afr Med J 1987;71:307-13.

27 Durie RM, Munroe AD. A prospective survey of injuries in a New Zealand schoolboy rugby population. New Zealand J Sports Med 2000;28:84-90.

28 Lee AJ, Garraway WM. Epidemiological comparison of injuries in school and senior club rugby. Br J Sports Med 1996;30:213-17.

29 Lindenfeld TN, Schmitt DJ, Hendy MP, et al. Incidence of injury in indoor soccer. Am J Sports Med 1994:22:364-71.

30 Dvorak J, Junge A, Chomiak J, et al. Risk factor analysis for injuries in football players - possibilities to design a preventive program. Am J Sports Med 2000;28(Suppl 5):S69-74.

31 Quarrie KL, Alsop JC P, Waller AE, et al. The New Zealand rugby injury and performance project. VI. A prospective cohort study of risk factors in rugby union football. Br J Sports Med 2001;35:157-66.

32 Junge A, Rösch D, Peterson $L$, et al. Prevention of soccer injuries-a prospective intervention study in youth amateur players. Am J Sports Med 2002:30:652-9.

33 Junge A, Chomiak J, Dvorak J. Incidence of football injuries in youth playerscomparison of players from two European regions. Am J Sports Med 2000:28(Suppl 5):S40-6.

34 Nathan M, Goedeke R, Noakes TD. The incidence and nature of rugby injuries experienced at one school during the 1982 rugby season. S Afr Med J 1983;64:132-7. 